\title{
Hexamerin-2 Protein of Locust as a Novel Allergen in Occupational Allergy
}

\author{
Yu Wang $\mathbb{D}^{1,2}$, Yuan Zhang ${ }^{3}$, Hongfei Lou ${ }^{3}$, Chengshuo Wang ${ }^{3}$, Ming Ni ${ }^{1}$, Dan $\mathrm{Yu}^{4}$, Luo Zhang $\mathbb{D}^{3}$, \\ Le Kang (D) ${ }^{1,5}$
}

'College of Life Science, Institute of Life Sciences and Green Development, Hebei University, Baoding, Hebei Province, People's Republic of China; ${ }^{2}$ College of Food Science and Technology, Hebei Agricultural University, Baoding, Hebei Province, People's Republic of China; ${ }^{3}$ Department of Otolaryngology Head and Neck Surgery, Beijing TongRen Hospital, Capital Medical University, Beijing, People's Republic of China; ${ }^{4}$ State Key Laboratory of Integrated Management of Pest Insects and Rodents, Institute of Zoology, Chinese Academy of Sciences, Beijing, I00I0I, People's Republic of China; ${ }^{5}$ Guangzhou Laboratory, Guangzhou, 510320, People's Republic of China

Correspondence: Le Kang, College of Life Science, Hebei University, Baoding, Hebei Province, People's Republic of China, Email Ikang@ioz.ac.cn; Luo Zhang, Department of Otolaryngology Head and Neck Surgery, Beijing Tongren Hospital, Capital Medical University, No. 17, Hougou Hutong, Dongcheng Beijing Institute of Otolaryngology, District, Beijing, I00730, People’s Republic of China, Email dr.luozhang@I39.com

Background: Occupational exposure to locusts induces a high prevalence of allergic sensitization. However, knowledge on occupational locust allergens remains unclear.

Objective: This study aimed to identify the allergens from locusts causing occupational allergies.

Methods: We conducted a survey of 57 persons exposed to locusts using questionnaires and immunological tests for occupational allergies in long-term locust laboratories. The major allergen was identified by immunoblotting and analysed by mass spectrometry. The allergenicity of the allergen was assessed by sIgE detection, immunoblotting and ELISA inhibition assays.

Results: The survey indicated that the frequency of locust occupational allergies was $40.4 \%$ among subjects exposed to locust. The symptoms in most males were allergic rhinitis, while females showed higher prevalence of atopic dermatitis. Occupational exposure increased the allergy risk. The recombinant hexamerin-2 protein possesses high allergenicity in the allergic exposure group. Hexamerin-2 protein can inhibit IgE reactivity with locust protein extracts by approximately $60 \%$. The potential for cross-reactivity with cockroaches was indicated by sequence alignment of hexamerin-2 protein and allergens of cockroaches.

Conclusion: The hexamerin-2 protein of locusts as an important allergen was identified. Therefore, occupational exposure is an important risk factor for locust allergy.

Keywords: locust, Locusta migratoria, occupational allergy, hexamerin-2 protein, contact dermatitis, asthma

\section{Introduction}

Occupational exposure to insects induces a high prevalence of allergic sensitization, which can lead to clinical inhalant allergies and contact allergies. ${ }^{1,2}$ Insect species of at least 12 different orders have been implicated in the promotion of inhalant allergies in humans, including locusts, cockroaches, and honeybees. ${ }^{3}$ Orthopteran insects, including grasshoppers, locusts, and crickets, are important occupational hazards because of the severe symptoms caused by insect allergens. $^{4-6}$

Locusts are not only one of the world's most destructive agricultural pests but also model systems in many laboratories for studying behaviour, physiology, neuroscience, and phenotypic plasticity. ${ }^{7,8}$ Several cases of occupational allergies have been described as allergies to the migratory locust, American locusts and grasshoppers, with symptoms of asthma, dermatitis, rhinitis and even shock. ${ }^{9}$ Moreover, a survey of the work-related symptoms indicated wheezing or breathlessness accounted for $26 \%$ of the symptoms, followed by rhinitis, asthma and urticaria. ${ }^{10}$ Questionnaires, skin prick tests (SPTs) and sIgE measurements showed that 25-55\% of individuals working in a research centre were allergic to locusts. ${ }^{5,6,11}$ Even dead locusts can induce severe contact urticaria in zookeepers 
during feeding of reptiles with the migratory locusts. ${ }^{12}$ In addition, locusts are also consumed worldwide for human food in Africa, South America, and Asia, both in rural and urban areas. ${ }^{13,14}$ Today, the locusts (deep-fried) are one of the best-known and most popular edible insects, they are an important food source as adding proteins and fats to the daily diet, especially in times of food crisis. Commercial farming of locusts for food and feed is developing in Southeast Asia. ${ }^{15-18}$ After being consumed by humans, locusts can induce (IgE-mediated) sensitization and development of respiratory, eye and skin symptoms, as well as allergic asthma. ${ }^{19-23}$ Approximately 27 cases of anaphylactic shock caused by consumption of grasshoppers and 27 cases caused by consumption of locusts were reported from 1980 to $2007 .{ }^{24}$ Therefore, identification of the major allergens from locusts is urgently needed to diagnose locustspecific allergies so as to prevent or reduce the serious consequences caused by occupational exposure or ingestion of locusts.

Research on the identification of allergens from the migratory locusts (Locusta migratoria) is highly preliminary, although many proteins are considered possible allergens to humans. Among the proposed locust protein spectra, the most likely allergens identified by immunoblotting approximately ranged from 18 to $130 \mathrm{kDa}$ in molecular weight. ${ }^{3,5,6,25}$ The above inconsistent findings suggested that the major allergens of locusts and their molecular nature remain unclear. Thus, the aim of the present study is to focus on the population who have exposure history from rearing and breeding locusts and explore the clinical conditions of occupational locust allergy in specific exposure settings and identify the new major allergens from locusts that causes occupational allergies.

\section{Materials and Methods}

\section{Subjects}

The occupational locust allergic questionnaire surveys were performed through a survey involving 57 scientists and students (24 males, 33 females) in the two laboratories at the Institute of Zoology, Chinese Academy of Sciences (Beijing, China) and College of Life Science, Hebei University (Baoding, Hebei Province, China). All of the subjects exposed to the migratory locust, Locusta migratoria, which were bred in a large confined space.

We collected serum samples from 57 subjects with history of exposure to locusts and 10 healthy controls without exposure history and allergy symptoms. Total IgE levels and sIgE levels for common inhalant allergens (willow, elm, poplar, ragweed, mugwort, cat, dog, cockroach and house dust mite) were measured by the UniCAP allergen detection system (Pharmacia Diagnostics, Uppsala, Sweden). The study adhered to the Declaration of Helsinki and it was approved by the ethics committee of Affiliated Hospital of Hebei University (authorization NO. HDFY-LL-2020-166) and all subjects signed informed consent forms prior to enrolment in the study.

\section{Preparation of Locust Protein Extracts}

The migratory locusts reared with a diet of fresh wheat seedlings were obtained from colonies maintained in the College of Life Science, Hebei University, Hebei Province, China. The samples were ground to a powder in a mortar and pestle using liquid nitrogen, then solubilized in PBS $(0.01 \mathrm{M}, \mathrm{pH} 7.2)$, the mixture was centrifuged at $12,000 \times \mathrm{g}$ for $15 \mathrm{~min}$ at $4^{\circ} \mathrm{C}$, and the supernatant was collected. The total protein content was determined by the BCA (Bicinchoninic acid) method.

\section{Skin Prick Tests}

SPT against crude protein extracts $(2.0 \mathrm{mg} / \mathrm{mL})$ of locusts and commercial extracts of Blattella germanica (produced by Beijing Union Hospital) was conducted, histamine was used as the positive control, and $0.9 \%$ saline was used as the negative control. The SPT results were recorded 15 minutes later. The wheal size was calculated as the mean of the longest diameter and the length of the perpendicular line through its middle. The ratio of the allergen wheal size to histamine wheal size was the skin index. The skin index was expressed as $2+$ when the wheal diameter was half that of the positive control and $3+$ when the mean wheal diameter was equal to that of the positive control. Allergy to locust was defined as skin index $\geq 2+$ combined with allergic symptoms. Sensitization to locust was defined as skin index $\geq 2+$ but without allergic symptoms after locust exposure. Non allergy was defined as skin index $<2+$ and no allergic symptoms after locust exposure. 


\section{ELISA of slgE for Locust Protein Extracts}

One hundred $\mu \mathrm{L}$ of the crude locust protein extracts $(500 \mu \mathrm{g} / \mathrm{mL})$ adjusted in PBS (0.01 M, pH 7.2) were added to ELISA plates (BBI, Sangon Biotech, Shanghai, China) and incubated overnight at $4^{\circ} \mathrm{C}$. After blocking with skimmed milk in PBS $(5 \%)$ at $37^{\circ} \mathrm{C}$ for $2 \mathrm{~h}$, the plate was washed 3 times in PBS containing $0.05 \%$ Tween 20 (PBST). Wells were then emptied and coated for $2 \mathrm{~h}$ with $100 \mu \mathrm{L}$ of sera from individuals and controls $(1: 30(\mathrm{v} / \mathrm{v})$, diluted with $5 \%$ skimmed milk in PBS) at $37^{\circ} \mathrm{C}$. Bound IgE was detected by adding $100 \mu \mathrm{L}$ of horseradish peroxidase (HRP)-labelled goat anti-human IgE (Abnova, Taiwan) (1:3000 dilution). 3,3',5,5'-Tetramethylbenzidine (TMB) was used as the substrate, and the reaction was stopped by $50 \mu \mathrm{L}$ of $2 \mathrm{M} \mathrm{H}_{2} \mathrm{SO}_{4}$. The absorbance of each well was measured at $450 \mathrm{~nm}$ using plate reader (Multiskan SkyHigh, Thermo Scientific, USA). The cut-off level was established as average of values from 10 nonallergic serum controls plus 3 times standard deviation and applied by SPSS 24.0 software (SPSS Inc., Chicago, USA). All other results above this level (plus standard deviations) are then considered positive.

\section{SDS-Polyacrylamide Gel Electrophoresis Analysis and IgE Immunoblotting}

The crude protein extracts were separated in triplicate by SDS-polyacrylamide gel electrophoresis (SDS-PAGE). Samples $(50 \mu \mathrm{g})$ were loaded onto an SDS-PAGE gel (10\% separating gel and $4 \%$ stacking gel) at $20 \mu \mathrm{L} /$ lane and electrically separated by the Mini-PROTEIN Tetra system (Bio-Rad; Hercules, CA, USA). The gels were stained with Coomassie Brilliant Blue R-250. For immunodetection of IgE-binding proteins, the separated proteins were electroblotted onto a polyvinylidene fluoride (PVDF) membrane (Immobilon, Merck Millipore, Germany) by applying a constant current of $350 \mathrm{~mA}$ for $55 \mathrm{~min}$ at room temperature. After blocking with 5\% skimmed milk in PBST, the membrane was incubated overnight at $4{ }^{\circ} \mathrm{C}$ with a $1: 30$ dilution in $5 \%$ skimmed milk of positive pooled sera, positive individual sera and negative pooled sera. Bound IgE antibodies were detected using HRP-conjugated goat anti-human IgE (Abnova, Taiwan) at a dilution of 1:10,000 in 5\% skimmed milk. The membrane was incubated with Super Signal ECL Chemiluminescent Substrate (Thermo Scientific, USA).

A band at approximately $70 \mathrm{kDa}$ from the locust proteins, recognized by immunoblotting of the pooled sera of locustallergic patients, was analysed by mass spectrometry, and the peptide sequences obtained were aligned with the migratory locust proteome at Beijing Protein Innovation.

\section{Cloning, Expression, and Purification of the Hexamerin-2 Protein from Locust}

On the basis of the results of mass spectrometry, the hexamerin-2 protein as a $\sim 70 \mathrm{kDa}$ protein with the highest sequence coverage (43\%) of peptide spectrum matching might be the best candidate allergen of the locusts. Therefore, we cloned, expressed and purified the hexamerin-2 protein and assessed the IgE sensitization prevalence among subjects with locust allergy $(n=23)$. Total RNA was isolated from the whole body of the migratory locusts by using TRIzol reagent (Invitrogen, Thermo, USA). Complete open reading frames (ORFs) for the hexamerine-2 protein were amplified from the cDNA using the PCR primers HEXA-2-F (5'-GTGCTGCATCGCGAGGACAC-3') and HEXA-2-R (5'-GTCGAAATGCGCGTTGGGCA $\left.-3^{\prime}\right)$. A construct was created by cloning the hexamerin-2 gene into the plasmid pET 30a vector and expressed in Escherichia coli BL21, then purified by Ni Sepharose 6 Fast Flow (GE Healthcare, USA). Expression and purification of the hexamerin-2 protein were conducted by Beijing Protein Innovation. SDS-PAGE was used to characterize the recombinant hexamerin-2 protein.

\section{Immunological Tests of the Hexamerin-2 Protein in Sera from Patients with Occupational Locust Allergy}

For the ELISA, $100 \mu \mathrm{L}$ of the hexamerin-2 protein $(500 \mu \mathrm{g} / \mathrm{mL})$ were added to ELISA plates (BBI, Sangon Biotech, Shanghai, China) and incubated overnight at $4^{\circ} \mathrm{C}$. After this, the ELISA was continued as previously described.

For the immunoblotting assay, SDS-PAGE-resolved hexamerin-2 protein were electro-transferred onto a PVDF membrane (Immobilon, Merck Millipore, Germany) for immunoblotting analysis as described above. Membranes were incubated with patient sera, diluted 1:30 (v/v) in 5\% skim milk-PBST, overnight at $4{ }^{\circ} \mathrm{C}$ under constant agitation and probed with 1:10,000 (v/v) anti-human IgE peroxidase antibody (Abnova, Taiwan) for $1.5 \mathrm{~h}$ at room temperature. 


\section{Competitive Inhibition ELISA}

In inhibition experiments, coating of the microtiter plates with crude protein extracts was performed as described above for ELISA. ${ }^{26}$ Two individual sera that showed positive reactions against the hexamerin-2 protein were chosen for inhibition studies. Sera were first incubated for $1 \mathrm{~h}$ at room temperature with an equal volume of the inhibitor solution. The final concentrations of the purified proteins used as inhibitors ranged from $0.005 \mu \mathrm{g} / \mathrm{mL}$ to $500 \mu \mathrm{g} / \mathrm{mL}$. Mixtures containing the sera and the inhibitor (or serum without inhibitor as a control) were incubated in the wells for $2 \mathrm{~h}$ at room temperature. After this, the ELISA was continued as previously described.

\section{Statistical Analysis}

Statistical significance was analysed by using GraphPad Prism 6.0 (GraphPad Inc., California, USA) and SPSS 24.0 software (SPSS Inc., Chicago, USA), and the values are presented as the mean \pm S.D. (standard deviation). T-test and one-way ANOVA were employed to analyse the nonparametric data. A P value of less than 0.05 was considered statistically significant.

\section{Results}

\section{Clinical Characteristics}

Our occupational locust allergic questionnaire surveys showed that the period of latency for the onset of sensitized symptoms varied, ranging from approximately one month to 20 years, with a mean interval of 3.9 years. Twenty-three out of 57 subjects exposed to locusts (40.4\%) were sensitized to locusts according to the SPT (Figure 1A, Table 1). Among the 23 locust-sensitized subjects, 18 were diagnosed with occupational allergy, with allergic rhinitis $(72.2 \%)$ as the most common symptom, followed by atopic dermatitis $(61.1 \%)$, asthma (27.8\%) and conjunctivitis $(5.6 \%)$, whereas the other 5 subjects were just sensitized to locusts (Figure 1B, Table 1). Although the number of allergic patients was similar among males (11) and females (12), males had a higher sensitization ratio $(45.8 \%, 11 / 24)$ than females $(36.4 \%, 12 / 33)$ (Figure 1A). More male patients complained of allergic rhinitis and asthma, while $70 \%$ of female patients suffered from atopic dermatitis (Figure 1B). One student (P3) had a severe allergic reaction to locusts, with difficulty breathing and asthma and even anaphylaxis once he went into the insectary.

The total IgE level in three subjects was less than $60 \mathrm{kU} / \mathrm{L}$, while in others, the level ranged from 69.3 to $1920 \mathrm{kU} / \mathrm{L}$ (Table 1). Moreover, 9 of the 23 locust-sensitized individuals were also sensitized to cockroaches, as determined by the SPT (Table 1). The previous allergy history showed an effect on allergy to locusts. Among locust-sensitized subjects, 14 patients $(14 / 23,60.9 \%)$ had a previous allergic history, whereas 9 patients $(9 / 23,39.1 \%)$ were not previously allergic $(\mathrm{P}<0.001)$ (Figure 1C). This indicated that past history of allergy might be a risk factor for locust allergy. We also found the duration of exposure was a risk factor for occupational allergy, exposure lasting for $2-3 \mathrm{~h}$ per day $(\mathrm{OR}=4.225)$ and continuing for one and half years $(\mathrm{OR}=2.842)$ obviously increased the risk of locust allergy (Figure 1D).

\section{Identification of the Major Allergens in Locusts}

To further confirm the sensitization of the persons exposed to locusts, we conducted in vitro experiments as well. The sIgE for locust proteins in patients' sera was detected by ELISA, the sIgE levels of the allergic group (absorbance at 450 $\mathrm{nm}$ was $1.174 \pm 0.136)$ were significantly higher than those of the non-allergic exposed group $(0.177 \pm 0.014)$ and healthy group $(0.174 \pm 0.020)$, while the sensitized group $(0.710 \pm 0.099)$ were not significantly higher (Figure $2 \mathrm{~A}$ ).

To determine the molecular weights of possible locust allergens, the locust protein extracts separated by SDS-PAGE were transferred to a PVDF membrane for immunoblotting with a serum pool of 10 sera (Table 1: P1-P10). Although the bands from the locust extracts ranged from 30 to $80 \mathrm{kDa}$, significant major bands at 56 and $70 \mathrm{kDa}$ were observed (Figure 2B). When the locust extract immunoblots were probed with 9 individual sera, only a 70-kDa band was observed in all 9 sera (Figure 2C). 
A

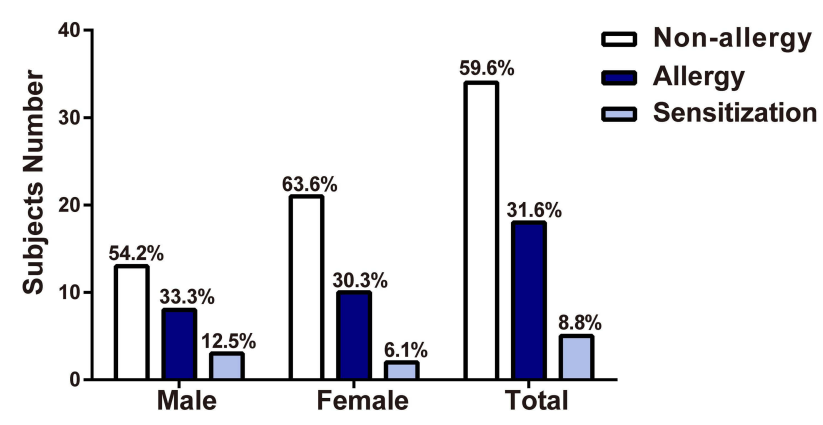

C

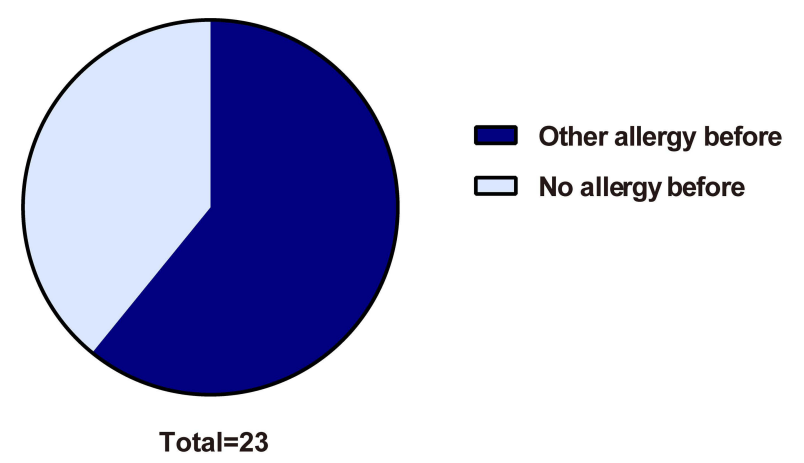

B

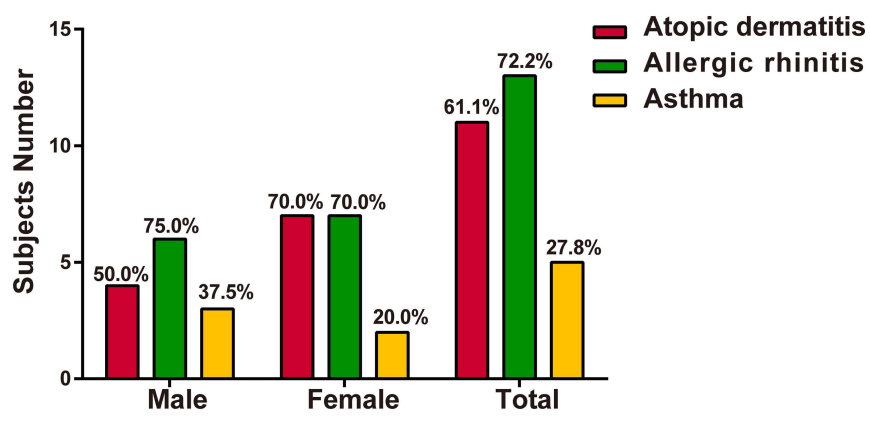

D

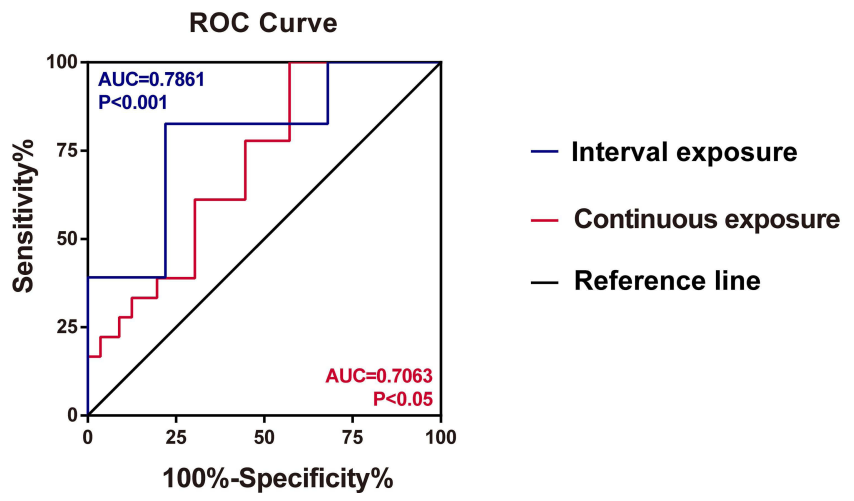

Figure I The survey of locust allergy in a cohort of 57 subjects. (A) Number of subjects sensitized to locust (males, females and total). (B) Suspected allergic disorders to locust in subjects (males, females and total). (C) Effect of other allergic histories on occupational allergies to locusts. (D) ROC curve of interval exposure and continuous exposure. The blue line was interval exposure indicating occupational exposure lasting for $2-3 \mathrm{~h}$ per day. The red line was continuous exposure indicating occupational exposure continuing for one and half year.

\section{The $70-\mathrm{kDa}$ Protein is the Hexamerin-2 Protein of Locusts}

To identify the protein with the band at $\sim 70 \mathrm{kDa}$, we analysed the $70-\mathrm{kDa}$ IgE-binding band of the locust extracts by mass spectrometry. Peptide spectrum matching gave the highest sequence coverage (43\%) with a hexamerin-2-like protein (NCBI: ACU78069.1), annotated as a storage protein, the juvenile hormone (JH)-binding protein in locusts (Figure 3A).

Then, we cloned the cDNA of the locust hexamerin-2 protein ORF, which covers 2031 nucleotides. The nucleotide sequence could be translated to a protein sequence with 677 amino acids, and the first 20 amino acids were predicted as a signal peptide. The calculated molecular mass of the hexamerin-2 protein was 78,663 Da, with a $\mathrm{pI}$ of 5.76. According to sequence structure analysis, the hexamerin-2 protein has 3 domains, and there is evidence to indicate that these domains are Hemocyanin-N domain, Hemocyanin-M domain and Hemocyanin-C domain (Figure 3B and C).

\section{Immunological Characterization of the Hexamerin-2 Protein}

To determine the sensitization to the hexamerin-2 protein, the ELISA assay was used to measure sIgE against the purified hexamerin-2 protein from locusts. The levels in the sera of 18 patients with locust allergy (absorbance at 450 $\mathrm{nm}$ was $1.174 \pm 0.575)$ were markedly higher than those in 5 sensitized patients $(0.710 \pm 0.099)$. Hexamerin-2 could not be detected by non-allergic sera $(0.520 \pm 0.083)$ and controls $(0.524 \pm 0.044)$ (Figure $4 \mathrm{~A})$. Immunoblotting was performed using individual sera from 9 locust-allergic patients, and the individuals reacted positively to the hexamerin-2 protein, while the control reacted negatively (Figure 4B). Therefore, the hexamerin-2 protein is an important allergen in locusts. 
Table I Patient Information, Allergy Symptoms, Total IgE Values (kU/L) and SPT Results

\begin{tabular}{|c|c|c|c|c|c|c|}
\hline No. & Gender & Age & Allergic Disorder or Symptoms & Total-IgE (kU/l) & L. migratoria SPT & B. germanica SPT \\
\hline $\mathrm{PI}$ & $\mathrm{F}$ & 24 & Difficulty breathing, AS & 1920 & +++ & ++ \\
\hline P2 & M & 35 & $A S, A R, A D$ & 923 & +++ & +++ \\
\hline P3 & M & 36 & Difficulty breathing, AS & 428 & +++ & l \\
\hline P4 & $\mathrm{F}$ & 23 & $A D$ & 420 & ++ & - \\
\hline P5 & $\mathrm{F}$ & 26 & AR & 359 & +++ & ++ \\
\hline P6 & $\mathrm{F}$ & 29 & $A S, A R, A D$ & 300 & +++ & I \\
\hline P7 & M & 27 & $A R, A D$ & 254 & +++ & ++ \\
\hline P8 & $\mathrm{F}$ & 26 & $A D$ & 196 & ++ & - \\
\hline P9 & $M$ & 29 & $A R, A D$ & 188 & +++ & ++ \\
\hline PIO & $M$ & 30 & $A D$ & 182 & ++ & - \\
\hline PII & $\mathrm{F}$ & 26 & $A D, A R$ & 179 & ++ & - \\
\hline $\mathrm{PI} 2$ & $\mathrm{~F}$ & 23 & $A R$ & 113 & ++ & - \\
\hline $\mathrm{PI} 3$ & $\mathrm{~F}$ & 28 & AR & 91.3 & +++ & - \\
\hline $\mathrm{PI} 4$ & $\mathrm{~F}$ & 28 & $A R, A D, C$ & 74 & ++ & - \\
\hline PI5 & $M$ & 43 & $A S, A R, A D$ & 69.7 & ++ & I \\
\hline PI6 & $\mathrm{F}$ & 27 & $A D$ & 69.3 & ++ & - \\
\hline PI7 & $M$ & 27 & $A D$ & $<60$ & ++ & - \\
\hline PI8 & $\mathrm{F}$ & 23 & $A D, A R$ & $<60$ & ++ & - \\
\hline PI9 & $M$ & 27 & - & 381 & ++ & + \\
\hline P2O & $\mathrm{F}$ & 23 & - & 179 & +++ & ++ \\
\hline P2I & $\mathrm{F}$ & 28 & - & 155 & ++ & - \\
\hline P22 & $M$ & 29 & - & 136 & ++ & ++ \\
\hline P23 & $M$ & 41 & - & $<60$ & ++ & ++ \\
\hline
\end{tabular}

Notes: +When the wheal diameter was $\geq 3 \mathrm{~mm}$; ++When the wheal diameter was half that of the positive control; +++When the mean wheal diameter was identical to the positive control; -, negative results; /, absent.

Abbreviations: F, female; M, male; AS, asthma; AR, allergic rhinitis; AD, atopic dermatitis; C, conjunctivitis.

To determine whether the hexamerin-2 protein is the major allergen in locusts, we chose two patients' sera (P2 and P3) with positive reactions to the hexamerin-2 protein for ELISA inhibition assays. The maximal inhibition of the binding of patients' IgE antibodies to the coated hexamerin-2 protein was approximately $60 \%$ (Figure 4C and D).

\section{Conservative Property of the Hexamerin-2 Protein in Insects}

We constructed a phylogenetic tree of the hexamerin-2 proteins of different grasshopper species, and the peptide sequences obtained were aligned with those of four grasshopper species (Chondracris rosea, Heteropternis respondens, Oedaleus asiaticus, Orinhippus tibetanus) (Figure S1). The similarity of the hexamerin-2 protein sequences of different grasshopper species was more than $93 \%$ (Figure S2). The hexamerin-2 protein of locusts shares $36.1 \%$ similarity with the allergen Bla g 3 (Blattella germanica); it also shares 53.3\% similarity with the allergen Per a 3 (Periplaneta americana) (Figure S3). By sequence alignment between the locust hexamerin-2 protein and shrimp hemocyanins, we found that 
A

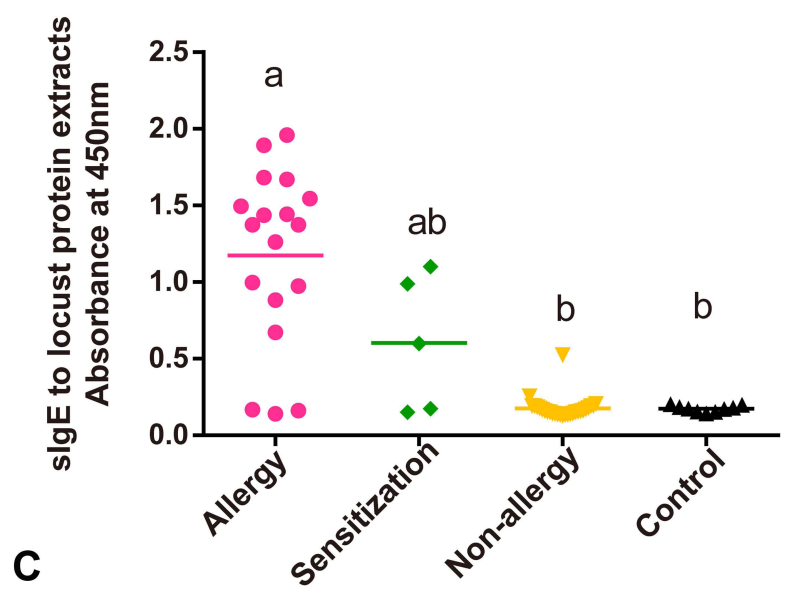

B

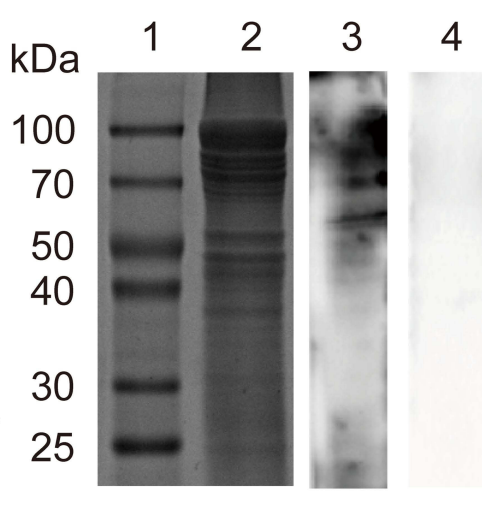

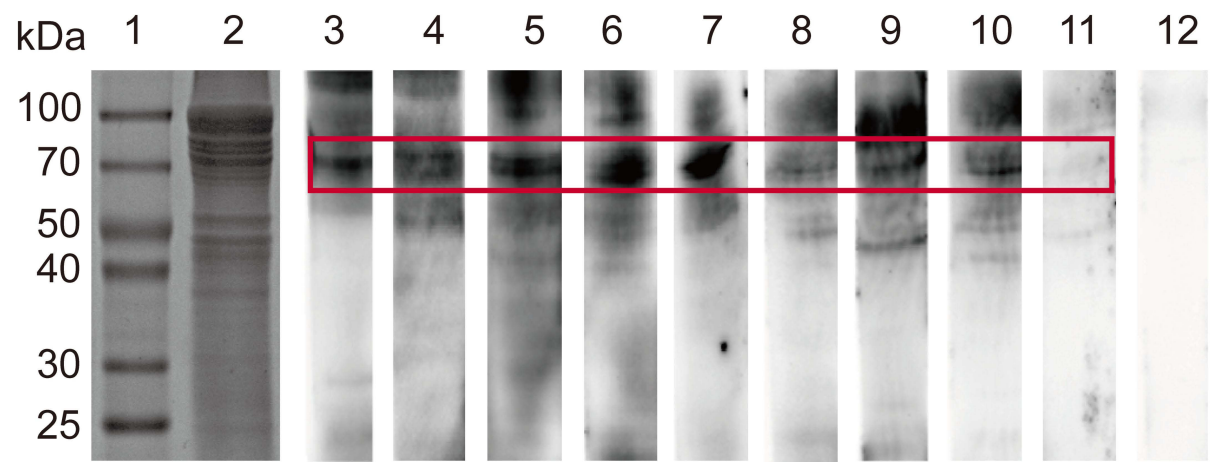

Figure 2 Identification of the sensitization to locust proteins of the subjects. (A) Measurement of slgE for locust proteins by ELISA. Statistically significant differences are shown using different letters above the bars ( $P<0.05$, one-way ANOVA), a is significant different from b, ab is not different from a or b. (B and $\mathbf{C})$ slgE immunoblotting of locust protein. (B) Lane I, protein marker. Lane 2, SDS-PAGE of locust extracts protein. Lane 3, immunoblotting with sera pool from I0 locust-allergic subjects. Lane 4, immunoblotting with sera pool from 10 control subjects. (C) Lane I, protein marker. Lane 2, SDS-PAGE of locust extracts protein. Lanes 3-II, immunoblotting with individual serum from locust-allergic subjects. Lane 12, pooled sera from 10 control subjects.

their sequence similarity was only approximately 29\% (Figure S4). Therefore, the hexamerin-2 protein of locusts are species specific, despite being relatively conserved in insects and arthropods.

\section{Discussion}

Locusts are an important insect group inducing occupational allergies, causing sensitization and the development of allergic symptoms in a high proportion of exposed persons. However, little information is available on the prevalence of the allergic diseases. In this study, the frequency of the locust occupational allergy is as high as $40.4 \%$, and the occupational allergy should be integrated into practitioner training priorities.

The survey showed a similar frequency of occupational sensitization $(\sim 50 \%)$ to locusts as that observed in previous studies. ${ }^{3-6}$ Although the allergic disorders included atopic dermatitis, allergic rhinitis and asthma, most male patients with allergies exhibited difficulty breathing, as in asthma, while female patients showed a prevalence of atopic dermatitis. However, men and women do not have different divisions of labour, they did the similar work and in a common exposure environment, therefore these differences may be caused by the gender itself. Our results demonstrated that occupational exposure for 2-3 h per day and continuing 1.5 years increased the risk of locust allergy, especially exposure exceeding $2-3 \mathrm{~h}$ per day. This could prevent people from developing allergies while working continuously in work place. In addition, we found that people with a history of allergies had a higher incidence of allergies after exposure to locusts than people without a history of allergies( $\mathrm{p}<0.001)$. It suggests that people with allergy history should first pay attention to protection for allergy prevention when carrying out work related to locusts.

Although some studies have shown that locusts can induce allergic reactions, no native allergen has been purified and characterized from the migratory locust. In our study, we identified the hexamerin-2 protein as an important allergen of 
A

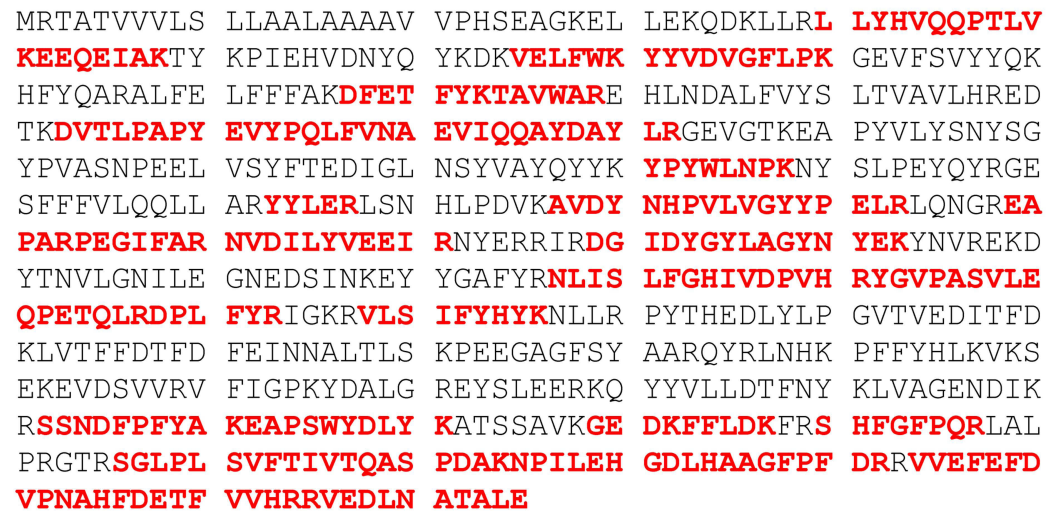

B

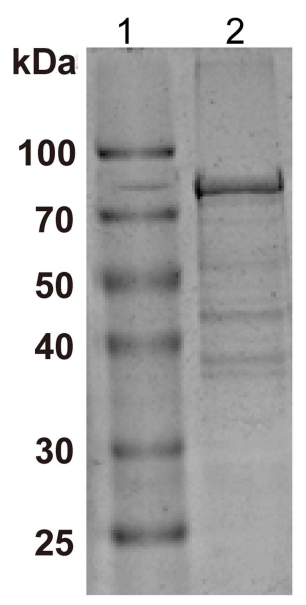

\section{C}

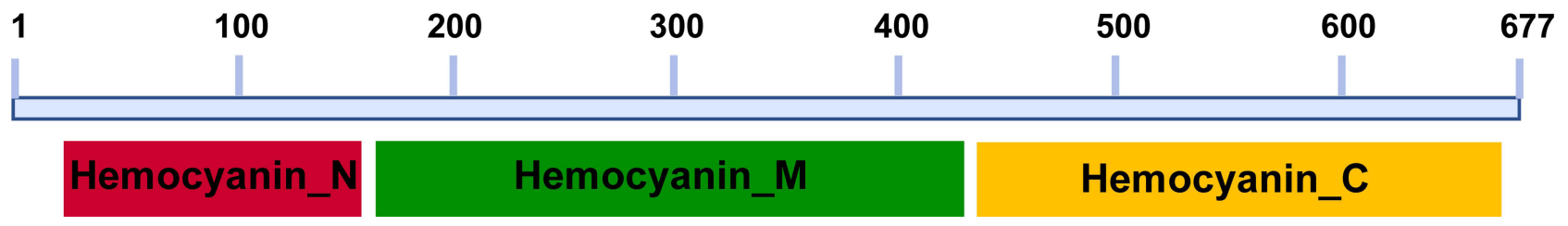

Figure 3 Mass analysis, peptide matches, purification and conserved domains analysis of hexamerin-2 protein. (A) Mature protein sequence, peptides verified by the mass spectrum fingerprint are shown in red and highlighted (NCBI accession ACU78069.I). (B) SDS-PAGE of the purified hexamerin-2 protein. Lane I, protein marker. Lane 2, SDS-PAGE of the hexamerin-2 protein. (C) Three domains of the hexamerin-2 protein were analysed in the NCBI database: hemocyanin-N domain, hemocyanin-M domain, hemocyanin-C domain.

occupational allergy to locusts. We proved for the first time the presence of the hexamerin-2 protein with IgE binding ability in locusts. ELISA inhibition assays indicated that maximal inhibition by the hexamerin-2 protein was approximately $60 \%$, suggesting that the locust hexamerin-2 protein was a predominant allergen accounting for IgE binding in the two patients whose sera were used for the inhibition experiment. Since the recombinant hexamerin-2 protein was not a much stronger inhibitor than the extract, it is fairly evident that other allergens also play a role. Therefore, further research to identify other allergens from locusts is necessary.

The hexamerin-2 protein, which is a storage protein in the hexamerin family in locusts, appears to be closely related to locust hemocyanin and associated with $\mathrm{JH}$ secretion. ${ }^{27}$ This allergen might be digested into peptides and could release to the locust breeding room by aerosol transmission. On the other hand, the hexamerin-2 protein widely exists in various species of orthopterans. ${ }^{28}$ These results indicated that humans are allergic to other locust and grasshopper species as well. Very recently, hexamerin-like protein 2 was also preliminarily identified as a cricket allergen through investigating the allergens involved in the allergic reactions experienced by two patients, who handled or ingested of crickets respectively, while its relationship with allergic symptoms, cross-reactivity with other insects, and prevalence in allergic patients were far from figuring out. ${ }^{29}$ The current study assumed that people who are allergic to shrimp might have allergic reactions to locusts, because sera from subjects allergic to shrimp could be used to identify allergens from Bombay locust. ${ }^{30}$ In our study, only one subject was allergic to aquatic products among the 23 subjects with locust allergy. Therefore, we considered there to be low cross-reactivity between shrimp and locusts, because the sequence similarity between the hexamerin-2 protein in locusts and hemocyanin in 3 shrimp species was only approximately $29 \%$.

The allergies to locusts and cockroaches in workers are associated with cross-reactivity. In our study, 39.1\% (9/23) of the locust-sensitized subjects tested positive against cockroach (B. germanica) in the SPT, and the sequence similarity of the hexamerin-2 protein in locusts and the allergen Blg 3 of $B$. germanica was $36.1 \%$. Moreover, the sequence similarity 
A

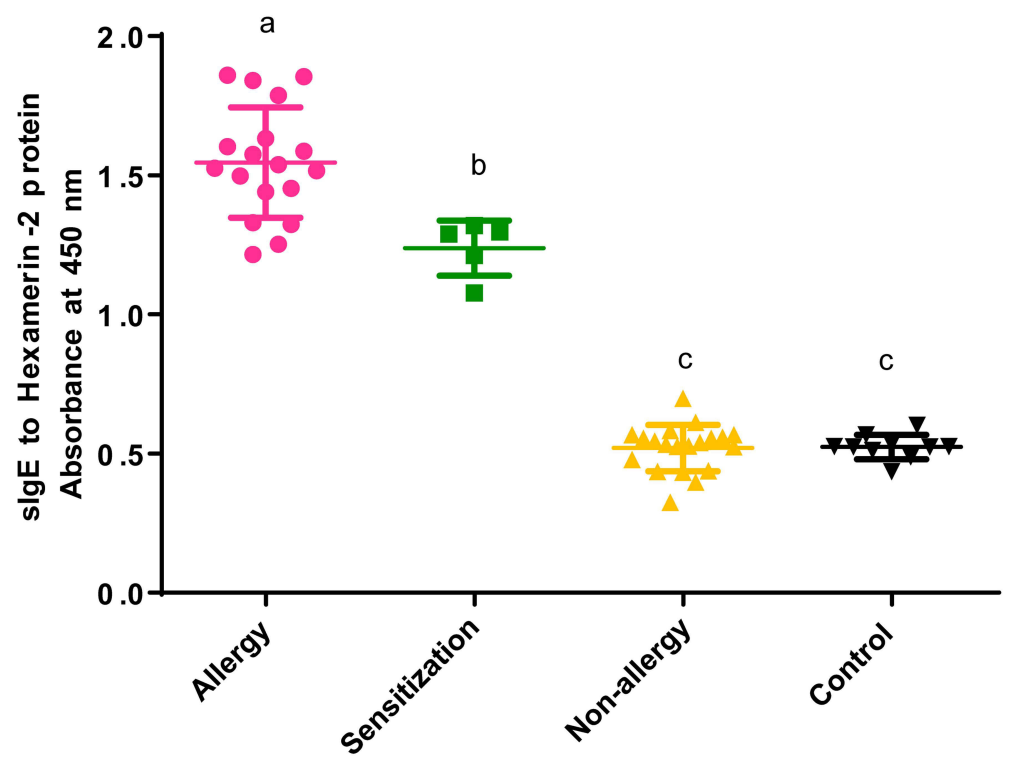

B

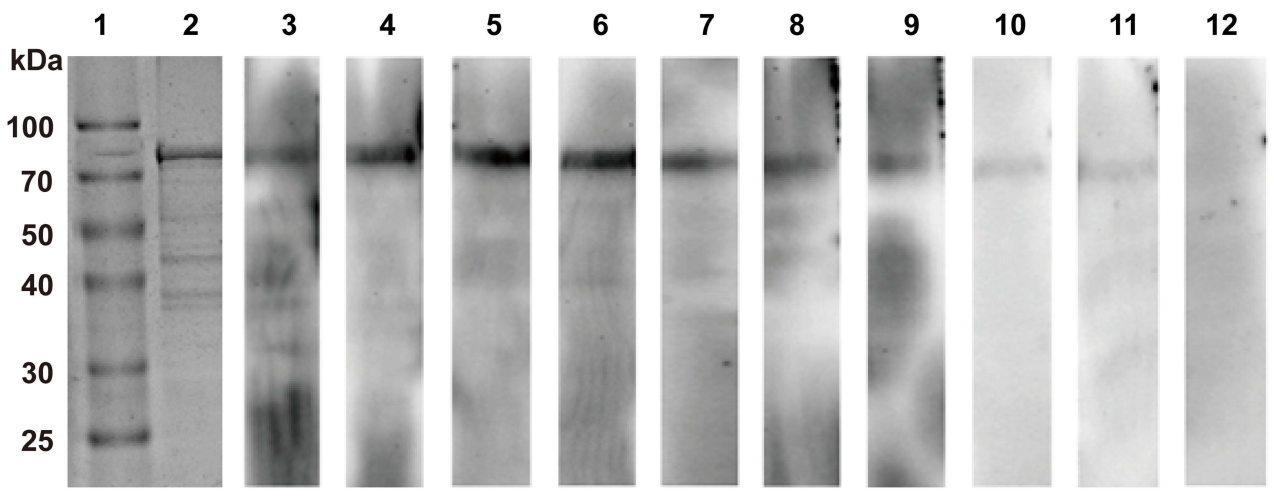

C

D

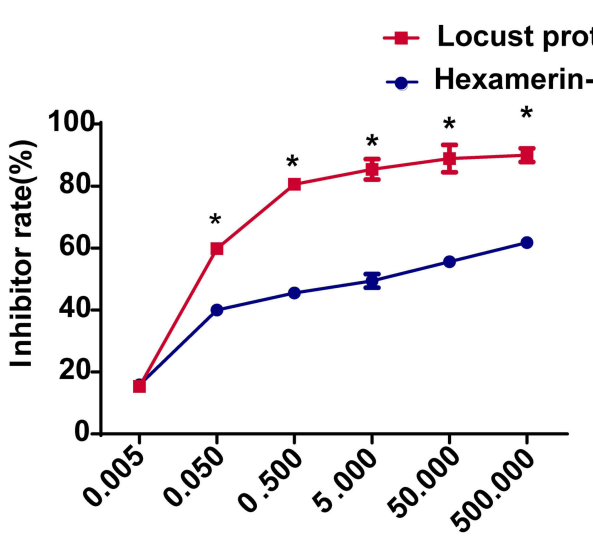

Inhibitor Concentration $(\mu \mathrm{g} / \mathrm{ml})$

\section{tracts \\ n}

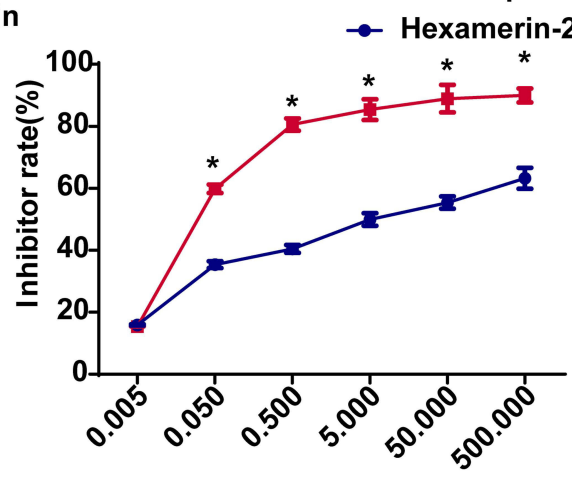

Inhibitor Concentration ( $\mu \mathrm{g} / \mathrm{ml}$ )

Figure 4 Identification of the sensitization to the hexamerin-2 protein of the subjects. (A) Measurement of slgE for the hexamerin-2 protein by ELISA. Statistically significant differences are shown using different letters (ie, a, b, c) above the bars ( $P<0.05$, one-way ANOVA). (B) slgE immunoblotting of Hexamerin- 2 protein. Lane I, protein marker. Lane 2, SDS-PAGE of the hexamerin-2 protein. Lanes 3-II, Immunoblotting with individual serum from 9 locust-allergic subjects. Lane I2, immunoblotting with sera pool from 10 control subjects. (C and D) Examination of serum IgE reactivity to the hexamerin-2 protein by competitive ELISA, representing the serum from locust-allergic patients $\mathrm{P} 2(\mathrm{C})$ and $\mathrm{P} 3(\mathrm{D})$, respectively. $\mathrm{P}$ values $<0.05$ were considered significant. 
between the hexamerin-2 protein in locusts and the allergen of $P$. americana was approximately $50 \%$. These low amino acid identities would most likely not be the basis for the cross-reactivity observed. Nevertheless, whether the crossreactivity between locust and need further research.

It is significant that the hexamerin-2 protein can be utilized to prepare diagnostic reagents in the future. On the other hand, desensitizers prepared with the hexamerin-2 protein will be beneficial to patients allergic to locusts, effectively relieving symptoms and reducing the health hazards of occupational exposure or other causes of allergies to locusts. In addition, because genomic and transcriptomic information available, ${ }^{7,31}$ the mechanisms of sensitization and epitopes of hexamerin-2 protein in locusts needs to be further investigated.

\section{Conclusions}

We identified the hexamerin-2 protein as an important allergen associated with occupational locust allergy. Recombinant molecules can be used for component-resolved diagnosis and to investigate locust allergies in the laboratory, to locusts used as food, and to locusts breeding in farms and fields.

\section{Acknowledgments}

We appreciate Feifei Cao from Beijing Tongren Hospital for her contribution in the SPT and sera detection by UniCAP. We would like to thank Ming Wang and Bing Yan from Beijing Key Laboratory of Nasal Diseases for their comments on this manuscript. All the subjects are acknowledged for their participation in our survey.

\section{Author Contributions}

All authors made a significant contribution to the work reported, whether that is in the conception, study design, execution, acquisition of data, analysis and interpretation, or in all these areas; took part in drafting, revising or critically reviewing the article; gave final approval of the version to be published; have agreed on the journal to which the article has been submitted; and agree to be accountable for all aspects of the work.

\section{Funding}

This study was supported by the special talent program of Hebei Province (Grant No. 070006-702800116049, 070006$702800117003)$.

\section{Disclosure}

All authors declare that they have no conflicts of interest.

\section{References}

1. Renström A, Malmberg P, Larsson K, et al. Prospective study of laboratory-animal allergy: factors predisposing to sensitization and development of allergic symptoms. Allergy. 1994;49(7):548-552. doi:10.1111/j.1398-9995.1994.tb01127.x

2. Seward JP. Occupational allergy to animals. Occup Med. 1999;14(2):285-304.

3. Lopata AL, Fenemore B, Jeebhay MF, et al. Occupational allergy in laboratory workers caused by the African migratory grasshopper Locusta migratoria. Allergy. 2005;60(2):200-205. doi:10.1111/j.1398-9995.2005.00661.x

4. Bellas TE. Occupational inhalant allergy to arthropods. Clin Rev Allergy. 1990;8:15-29. doi:10.1007/BF02914434

5. Soparkar GR, Patel PC, Cockcroft DW. Inhalant atopic sensitivity to grasshoppers in research laboratories. J Allergy Clin Immunol. 1993;92 (1):61-65. doi:10.1016/0091-6749(93)90038-H

6. Tee RD, Gordon DJ, Hawkins ER, et al. Occupational allergy to locusts: an investigation of the sources of the allergen. J Allergy Clin Immunol. 1988;81(3):517-525. doi:10.1016/0091-6749(88)90188-1

7. Wang XH, Fang XD, Yang PC, et al. The locust genome provides insight into swarm formation and long-distance flight. Nat Commun. 2014;5 (1):2957. doi:10.1038/ncomms3957

8. Kang L, Chen XY, Zhou Y, et al. The analysis of large-scale gene expression correlated to the phase changes of the migratory locust. Proc Natl Acad Sci U S A. 2004;101(51):17611-17615. doi:10.1073/pnas.0407753101

9. Pener PM. Allergy to locusts and acridid grasshoppers: a review. J Orthoptera Res. 2014;23:59-67. doi:10.1665/034.023.0105

10. Franklin AW. Locust sensitivity. Ann Allergy. 1953;11(4):445-453.

11. Burge PS, Edge G, O'Brien IM, et al. Occupational asthma in a research centre breeding locusts. Clin Exp Allergy. 1980;10(4):355-363. doi:10.1111/j.1365-2222.1980.tb02119.x

12. Rauschenberg R, Bauer A, Beissert S, et al. Occupational immediate-type allergy to locusts in a zookeeper. J Dtsch Dermatol Ges. 2015;13 (2):157-158. doi:10.1111/ddg.12442 
13. Huis AV, Oonincx D. The environmental sustainability of insects as food and feed. A review. Agron Sustain Dev. 2017;37(5):43. doi:10.1007/ s13593-017-0452-8

14. Huis AV, Itterbeeck JV, Klunder H, et al. Edible Insects: Future Prospects for Food and Feed Security. Rome, Italy: Food and Agriculture Organization of the United Nations (FAO); 2013.

15. Huis AV. Potential of insects as food and feed in assuring food security. Annu Rev Entomol. 2013;58(1):563-583. doi:10.1146/annurev-ento $-120811-153704$

16. Mohamed E. Determination of nutritive value of the edible migratory locust Locusta migratoria, Linnaeus, 1758 (Orthoptera: acrididae). Int $J A d v$ Pharm Biol Chem. 2015;4(1):144-148.

17. Feng Y, Chen XM, Zhao M, et al. Edible insects in China: utilization and prospects. Insect Sci. 2018;25(2):184-198. doi:10.1111/1744-7917.12449

18. Mariod AA, Mirghani M, Hussein I. Chapter 44 - schistocerca gregaria (Desert Locust) and Locusta migratoria (Migratory Locust). Unconventional Oilseeds and Oil Sources. Academic Press: Cambridge, MA; 2017:293-297.

19. Johansson SG, Hourihane JB, Bousquet J, et al. A revised nomenclature for allergy. An EAACI position statement from the EAACI nomenclature task force. Allergy. 2001;56(9):813-824. doi:10.1034/j.1398-9995.2001.t01-1-00001.x

20. Gier SD, Verhoeckx K. Insect (food) allergy and allergens. Mol Immunol. 2018;100:82-106. doi:10.1016/j.molimm.2018.03.015

21. Xu CL. Analysis of 24 cases of anaphylactic enteritis caused by locusts. Second National Allergy Soc Conf Chin Med Assoc. 2004 . Chinese Journal. Available from: https://kns.cnki.net/kcms/detail/detail.aspx dbcode=CPFD\&dbname=CPFD9908\&filename=ZHYX200410001282\&uniplatform= NZKPT\&v=700WU0tRjVq2HP4H_u1tZvHKNh2Stcwcgw0rNVSPOIhCG2PBzV300 ZQNSBQAc8jQ1HO4fwAT6qlgcM\%3d. Accessed January 25, 2022.

22. Du CJ. Analysis of 32 cases of allergic reaction to locusts. Chin J Civ Med. 2001;03:160. Chinese Journal.

23. Yu JB. Analysis of 9 cases of allergic reaction to locusts. Integr Clin Med. 1993;9(6):330. Chinese Journal.

24. Ji KM, Chen JJ, Li M, et al. Anaphylactic shocks and lethal anaphylaxis caused by food consumption in China. Trends Food Sci Technol. 2009;20:227-231. doi:10.1016/j.tifs.2009.02.004

25. Chen YK, Wu YL, Liu ZG. Purification and identification of allergens in Locusta migratoria manilensis. Chin J Appl Entomol. $2012 ; 49: 244-247$.

26. Ma D, Li Y, Dong J, et al. Purification and characterization of two new allergens from the salivary glands of the horsefly, Tabanus yao. Allergy. 2011;66:101-109. doi:10.1111/j.1398-9995.2010.02435.x

27. Braun RP, Wyatt GR. Sequence of the hexameric juvenile hormone-binding protein from the hemolymph of Locusta migratoria. $J$ Biol Chem. 1996;271(49):31756-31762. doi:10.1074/jbc.271.49.31756

28. Zhang GJ, Wang HS, Shi JJ, et al. Identification and characterization of insect-specific proteins by genome data analysis. BMC Genom. 2007;8 (1):93-103. doi:10.1186/1471-2164-8-93

29. Marinas ML, Cerdá JC, López-Matas MA, et al. Hexamerin- like protein 2, a cricket allergen involved in occupational and food allergy. Clin Exp Allergy. 2021;51:858-860. doi:10.1111/cea.13877

30. Phiriyangkul P, Srinroch C, Srisomsap C, et al. Effect of food thermal processing on allergenicity proteins in Bombay Locust (Patanga Succincta). Int J Food Eng. 2015;1(1):23-28.

31. Yang PC, Hou L, Wang XH, et al. Core transcriptional signatures of phase change in the migratory locust. Protein Cell. 2019;10(12):883-901. doi:10.1007/s13238-019-0648-6

Journal of Asthma and Allergy

Dovepress

\section{Publish your work in this journal}

The Journal of Asthma and Allergy is an international, peer-reviewed open-access journal publishing original research, reports, editorials and commentaries on the following topics: Asthma; Pulmonary physiology; Asthma related clinical health; Clinical immunology and the immunological basis of disease; Pharmacological interventions and new therapies. The manuscript management system is completely online and includes a very quick and fair peer-review system, which is all easy to use. Visit http://www.dovepress.com/testimonials.php to read real quotes from published authors.

Submit your manuscript here: https://www.dovepress.com/journal-of-asthma-and-allergy-journal 